Article

\title{
Modulation of Tidal Channel Signatures on SAR Images Over Gyeonggi Bay in Relation to Environmental Factors
}

\author{
Tae-Sung Kim ${ }^{1}$, Kyung-Ae Park ${ }^{2}$ and Moonjin Lee ${ }^{1, *}$ \\ 1 Marine Safety and Environmental Research Department, Korea Research Institute of Ships and Ocean \\ Engineering (KRISO), Daejeon 34103, Korea; tskim@kriso.re.kr \\ 2 Department of Earth Science Education, Seoul National University, Seoul 08826, Korea; kapark@snu.ac.kr \\ * Correspondence: moonjin.lee@kriso.re.kr; Tel.: +82-42-866-3614
}

Received: 27 February 2018; Accepted: 3 April 2018; Published: 6 April 2018

\begin{abstract}
In this study, variations of radar backscatter features of the tidal channel in Gyeonggi Bay in the Eastern Yellow Sea were investigated using spaceborne synthetic aperture radar (SAR) images. Consistent quasi-linear bright features appeared on the SAR images. Examining the detailed local bathymetry chart, we found that the features were co-located with the major axis of the tidal channel in the region. It was also shown that modulation of the radar backscatter features changed according to the environmental conditions at the time of imaging. For the statistical analysis, the bathymetric features over the tidal channel were extracted by an objective method. In terms of shape, the extracted features had higher variability in width than in length. The analysis of the variation in intensity with the coinciding bathymetric distribution confirmed that the quasi-linear bright features on the SAR images are fundamentally imprinted due to the surface current convergence and divergence caused by the bathymetry-induced tidal current variation. Furthermore, the contribution of environmental factors to the intensity modulation was quantitatively analyzed. A comparison of the variation in normalized radar cross section (NRCS) with tidal current showed a positive correlation only with the perpendicular component of tidal current $(\mathrm{r}=0.47)$. This implies that the modulation in intensity of the tidal channel signatures is mainly affected by the interaction with cross-current flow. On the other hand, the modulation of the NRCS over the tidal channel tended to be degraded as wind speed increased $(r=-0.65)$. Considering the environmental circumstances in the study area, it can be inferred that the imaging capability of SAR for the detection of tidal channel signatures mainly relies on wind speed.
\end{abstract}

Keywords: SAR; tidal channel; components of tidal current

\section{Introduction}

The measurement of ocean bathymetry is essential for the support of coastal environmental research, human activities, shipping, boating, and coastal surveillance for marine safety. In spite of an increasing interest in coastal environmental monitoring, there are still limitations in the use of bathymetric surveying due to the inefficiency of its methodology. Conventional bathymetry mapping is carried out with sonar systems on vessels, which are quite expensive and only cover regions with sparse shipping tracks. Considering that the depth, location, and shape of underwater features can vary with time due to the temporal and spatial variation in ambient currents, the importance of a remote sensing observation technique for the regular monitoring of a wide coastal area remains relevant.

Synthetic aperture radar (SAR) has the ability to detect shallow water bottom topography through the interaction between bathymetry and currents. Since variation in a current flowing over an 
underwater feature induces modulations in the sea surface roughness, underwater features can be indirectly imaged onto SAR images [1-12]. In particular, this spatial backscatter variation is more often and more clearly observed in shallow coastal zones with strong tidal currents [9,11-13].

The mechanism of bottom topography imaging on radar images was first proposed by Alpers and Hennings [1]. They described a radar imaging mechanism modulated by the interaction between the wind-generated sea surface wave spectrum with the sea surface currents, based on ane-dimensional continuity equation. Thus, it is assumed that the direction of tidal current flow is approximately normal to the orientation of the major axis of underwater bathymetric features. Models of this kind have been further improved by various researchers [2,4,14-21]. However, it has been reported that bathymetry imprints can also appear on SAR imagery when tidal current flows are parallel to the sand ridge orientation $[7,11,12]$. For the interpretation of SAR imaging of the along-sand-ridge-direction current interaction, the two-dimensional analytical model was developed [7]. Results from studies involving this model demonstrated that surface convergence and divergence zones induced by the modulation of surface flow fields interacted with cross-sand ridge components and became visible on spaceborne SAR images. Recently, in-depth verification of the imaging mechanisms for tidal channels and shallow sand ridges, whose major axes are roughly parallel to the semidiurnal tidal currents, has been achieved through further theoretical analysis [12].

Although the theoretical models may provide a fundamental understanding of the SAR imaging of shallow water topography, most of the previous research has focused on apparent imaging examples under certain favorable conditions. This is considered a limitation to providing the statistical properties of normalized radar cross section (NRCS) modulations on SAR images for regular monitoring. The objectives of this study are to identify tidal channel signatures from SAR images using an objective method, present the variations in the signatures in terms of radar intensity modulation, quantitatively analyze the effects of environmental factors on the NRCS, and investigate the relationship between the tidal channel signatures on SAR images and the effects of tidal current components.

\section{Data and Methods}

To investigate the variation in tidal channel signatures in SAR images, we collected SAR images with persistent features of the tidal channel in Gyeonggi Bay, which is located in the Eastern part of the Yellow Sea off the Western coast of the Korean Peninsula (Figure 1). The study area is characterized by a shallow water depth of less than $30 \mathrm{~m}$ and a high tidal range of about $8 \mathrm{~m}$. The surface current is dominated by a strong tidal current, flowing northeast in flood and southwest in ebb. As a macro-tidal regime, a number of tidal sand ridges and tidal channels prevail along with the axis of the tidal ellipses [22]. The sand ridges are composed of relict sediments, formed during the late Quaternary period, and their depositional patterns are primarily controlled by the strong tidal current system in the region $[23,24]$. Under these circumstances, it was anticipated that the interaction of bathymetry and strong tidal currents would produce significant convergent or divergent zones in the region, which appear as bright and dark intensity patterns on the SAR images. Figure 2 demonstrates an example of the SAR images of the study area, acquired on 11 December 2007. As expected, complicated shallow water topography features of sand ridges and tidal channels in Gyeonggi Bay are present in the SAR images. One can readily find two distinct curved lines, elongated from northeast to southwest in the middle part of the image (A and B in Figure 2). These tidal channel signatures show significantly higher variation in intensity compared to other sand ridge features. Underwater bathymetric signatures of sand ridges are also revealed. Radial sand ridges on various scales, which are formed from the river runoff, prevail around the coast and islands ( $C$ in Figure 2) but are not shown clearly on the image. In the current, we focus on the tidal channel signatures for the statistical investigation of NRCS modulation. 

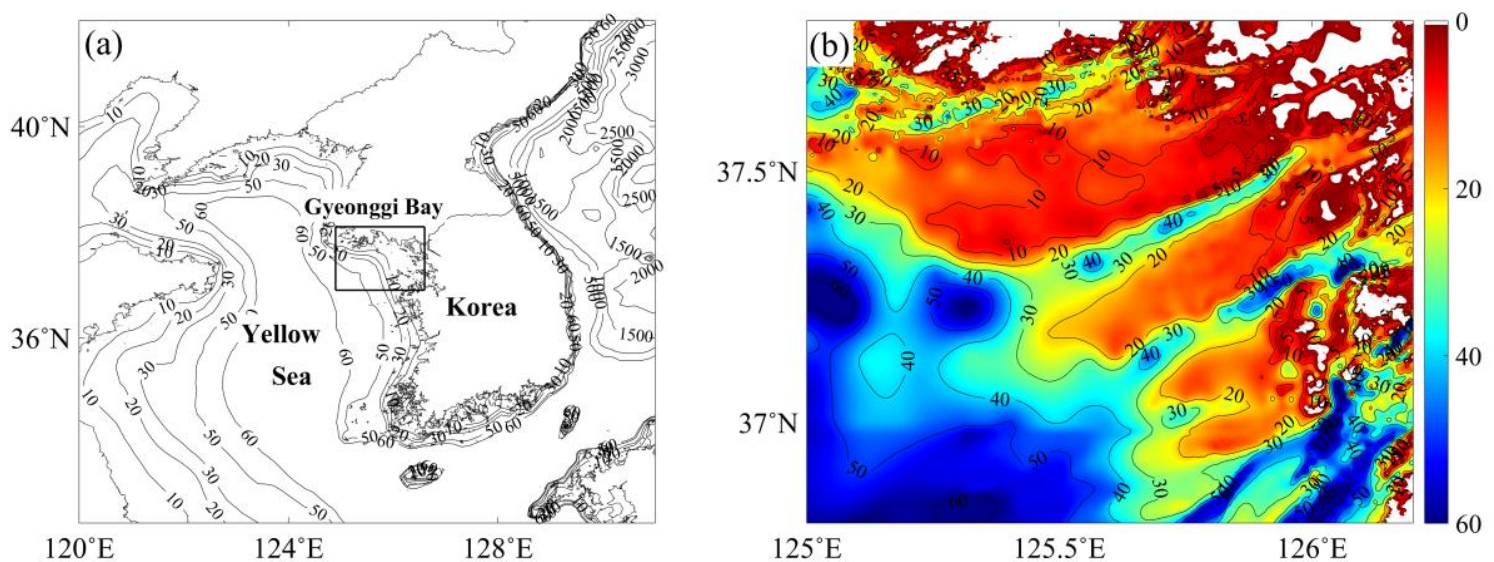

Figure 1. (a) Location of the study area with contours of the water depth (m), and (b) an enlarged bathymetry map of Gyeonggi Bay in the Yellow Sea (m). Bathymetric data were derived from Global Multi-Resolution Topography (GMRT) data.

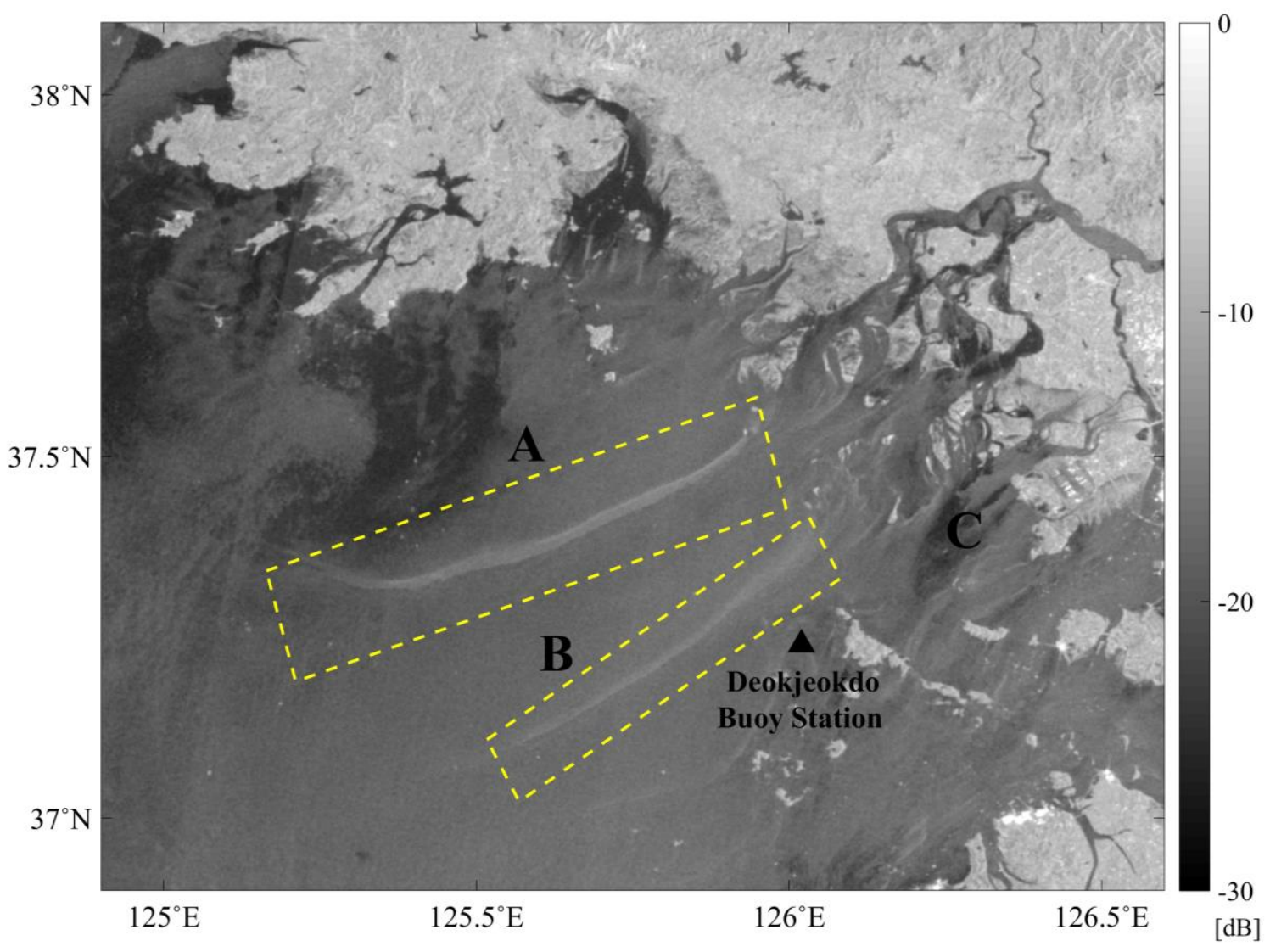

Figure 2. An example of a synthetic aperture radar (SAR) image at the study area off the Western coast of Korea, acquired on 11 December 2007, where the black triangle indicates the Korean Meteorological Administration (KMA) meteorological buoy station.

To illustrate the variation in the underwater bathymetric features, we collected all available scenes which fully covered the study area in the tidal channels from Environmental Satellite's (Envisat) Advanced Synthetic Aperture Radar (ASAR) and the Advanced Land Observing Satellite's (ALOS) Phased Array type L-band Synthetic Aperture Radar (PALSAR). As a result, a total of 13 SAR images taken over the study area were used in the study. The details of the SAR images are summarized in Table 1. The Envisat ASAR images used in this study were acquired from 2004-2007 at the C-band 
$(5.3 \mathrm{GHz})$ in a VV- or HH-polarization state with a pixel spacing varying from $12.5-75 \mathrm{~m}$, depending on the image acquisition mode. The ALOS PALSAR images were obtained from 2007-2009 at the L-band $(1.2 \mathrm{GHz})$ in an $\mathrm{HH}$-polarization state with a pixel spacing of $100 \mathrm{~m}$. Before extracting the tidal channel signatures, the SAR data were preprocessed to derive the NRCS and georeferenced using ancillary geolocation information. Then, pixels in the land areas were masked using digital elevation model data, while the remains were averaged in a $250 \mathrm{~m} \times 250 \mathrm{~m}$ moving window to reduce speckle noise. As shown in Figure 2, since the tidal channel signatures are mostly aligned over tens of kilometers along the range direction, progressive brightness reductions due to incidence angle dependence occurred across the images. This incidence angle-dependent variation from a near to far range may affect feature detection results [25]. Prior to feature detection, the square cosine correction method was applied to reduce the incidence angle effect $[26,27]$. Tidal channel signatures on the incidence angle-normalized SAR images were detected by the adaptive thresholding method [28,29]. This method objectively determines a threshold within each window with statistical parameters. Since it does not require any prior environmental knowledge, this method has been widely used for object detection in SAR images [28-31]. For the separation of the main underwater bathymetric signatures from irrelevant small surrounding features, all the detected features were clustered with neighboring pixels in the eight-direction. Among the clusters, features that were smaller than the minimum size $\left(1 \mathrm{~km}^{2}\right)$ were eliminated. Given that the edge detection algorithm shows much better results when implemented with an optimized image with little noise [32], the edges of the tidal channel signatures were extracted with a Canny edge detector [33] after discrimination of the main NRCS modulation features from the noisy background.

To investigate the contribution of environmental factors to NRCS variation over the tidal channel features, we used in-situ wind measurements obtained from the nearest Korean Meteorological Administration (KMA) meteorological buoy station, and tide data from the Tidal Prediction System of the Korea Research Institute of Ships and Ocean Engineering (KRISO-TPS). In-situ winds were measured at hourly intervals at $126.02^{\circ} \mathrm{E}, 37.24^{\circ} \mathrm{N}$ (Station ID: Deokjeokdo), as marked by the black triangle in Figure 2-approximately $26.7 \mathrm{~km}$ away from the major axis of the tidal channel signatures. KRISO-TPS is a tidal prediction package for producing tidal height and currents, with a database of tidal constituents derived from refined numerical simulations in the seas around Korea [34]. The wind and tidal current conditions from the dataset at the imaging time of the SAR images are summarized in Table 1. The bathymetry data from the study area were derived from Global Multi-Resolution Topography (GMRT) data with a pixel spacing of approximately $100 \mathrm{~m}$. Although the GMRT data have been generated and updated through the synthesis of high resolution seafloor bathymetry data collected from sonar surveys, international bathymetric charts, and elevation data [35], the main source of bathymetric data in the study area was seafloor depth data, with a grid spacing of 30 arc-seconds, from the General Bathymetric Chart of the Oceans (GEBCO). 
Table 1. Characteristics of the SAR images utilized in the study and environmental conditions at the imaging time. Directions are measured in degrees clockwise from due north.

\begin{tabular}{|c|c|c|c|c|c|c|c|c|c|c|c|c|c|}
\hline No. & 1 & 2 & 3 & 4 & 5 & 6 & 7 & 8 & 9 & 10 & 11 & 12 & 13 \\
\hline \multirow{2}{*}{ Satellite/Sensor } & Envisat & Envisat & Envisat & Envisat & Envisat & Envisat & Envisat & Envisat & Envisat & Envisat & ALOS & ALOS & ALOS \\
\hline & ASAR & ASAR & ASAR & ASAR & ASAR & ASAR & ASAR & ASAR & ASAR & ASAR & PALSAR & PALSAR & PALSAR \\
\hline \multirow{2}{*}{ Acquisition time } & 2004.04.07 & 2005.01.12 & 2005.04 .20 & 2005.04.27 & 2005.05.25 & 2005.10.19 & 2005.11.16 & 2006.04 .12 & 2007.12.11 & 2007.08.27 & 2007.03.19 & 2007.05 .04 & 2009.07.11 \\
\hline & $01 \mathrm{~h} 48 \mathrm{~m}$ & $01 \mathrm{~h} 48 \mathrm{~m}$ & $13 \mathrm{~h} 23 \mathrm{~m}$ & $01 \mathrm{~h} 49 \mathrm{~m}$ & $13 \mathrm{~h} 23 \mathrm{~m}$ & $01 \mathrm{~h} 49 \mathrm{~m}$ & $13 \mathrm{~h} 23 \mathrm{~m}$ & $01 \mathrm{~h} 48 \mathrm{~m}$ & $01 \mathrm{~h} 40 \mathrm{~m}$ & $13 \mathrm{~h} 26 \mathrm{~m}$ & $02 \mathrm{~h} 16 \mathrm{~m}$ & $02 \mathrm{~h} 16 \mathrm{~m}$ & $02 \mathrm{~h} 20 \mathrm{~m}$ \\
\hline $\begin{array}{l}\text { Frequency } \\
(\mathrm{GHz})\end{array}$ & $\begin{array}{c}5.3 \\
\text { (C-band) }\end{array}$ & $\begin{array}{c}5.3 \\
\text { (C-band) }\end{array}$ & $\begin{array}{c}5.3 \\
\text { (C-band) }\end{array}$ & $\begin{array}{c}5.3 \\
\text { (C-band) }\end{array}$ & $\begin{array}{c}5.3 \\
\text { (C-band) }\end{array}$ & $\begin{array}{c}5.3 \\
\text { (C-band) }\end{array}$ & $\begin{array}{c}5.3 \\
\text { (C-band) }\end{array}$ & $\begin{array}{c}5.3 \\
\text { (C-band) }\end{array}$ & $\begin{array}{c}5.3 \\
\text { (C-band) }\end{array}$ & $\begin{array}{c}5.3 \\
\text { (C-band) }\end{array}$ & $\begin{array}{c}1.2 \\
\text { (L-band) }\end{array}$ & $\begin{array}{c}1.2 \\
\text { (L-band) }\end{array}$ & $\begin{array}{c}1.2 \\
\text { (L-band) }\end{array}$ \\
\hline Polarization & $\mathrm{VV}$ & $\mathrm{VV}$ & $\mathrm{VV}$ & $\mathrm{VV}$ & $\mathrm{VV}$ & $\mathrm{VV}$ & $\mathrm{VV}$ & $\mathrm{VV}$ & $\mathrm{VV}$ & $\mathrm{HH}$ & $\mathrm{HH}$ & $\mathrm{HH}$ & $\mathrm{HH}$ \\
\hline \multirow[b]{2}{*}{ Central location } & $124.61^{\circ} \mathrm{E}$ & $126.07^{\circ} \mathrm{E}$ & $125.78^{\circ} \mathrm{E}$ & $126.06^{\circ} \mathrm{E}$ & $125.79^{\circ} \mathrm{E}$ & $126.07^{\circ} \mathrm{E}$ & $125.79^{\circ} \mathrm{E}$ & $126.07^{\circ} \mathrm{E}$ & $127.09^{\circ} \mathrm{E}$ & $126.27^{\circ} \mathrm{E}$ & $125.25^{\circ} \mathrm{E}$ & $125.26^{\circ} \mathrm{E}$ & $124.73^{\circ} \mathrm{E}$ \\
\hline & $37.58^{\circ} \mathrm{N}$ & $37.67^{\circ} \mathrm{N}$ & $37.30^{\circ} \mathrm{N}$ & $37.67^{\circ} \mathrm{N}$ & $37.30^{\circ} \mathrm{N}$ & $37.67^{\circ} \mathrm{N}$ & $37.30^{\circ} \mathrm{N}$ & $37.67^{\circ} \mathrm{N}$ & $36.87^{\circ} \mathrm{N}$ & $38.35^{\circ} \mathrm{N}$ & $37.99^{\circ} \mathrm{N}$ & $38.00^{\circ} \mathrm{N}$ & $37.99^{\circ} \mathrm{N}$ \\
\hline $\begin{array}{l}\text { Wind speed } \\
(\mathrm{m} / \mathrm{s})\end{array}$ & 4.0 & 8.5 & 6.0 & 9.3 & 5.1 & 3.1 & 4.6 & 3.4 & 4.7 & 4.1 & 4.6 & 5.6 & 2.4 \\
\hline $\begin{array}{l}\text { Wind direction } \\
\left({ }^{\circ}\right)\end{array}$ & 265 & 130 & 229 & 170 & 186 & 31 & 353 & 256 & 16 & 212 & 298 & 17 & 126 \\
\hline $\begin{array}{l}\text { Tidal current } \\
\text { velocity }(\mathrm{cm} / \mathrm{s})\end{array}$ & 89 & 99 & 72 & 94 & 38 & 75 & 105 & 44 & 76 & 70 & 58 & 64 & 103 \\
\hline $\begin{array}{c}\text { Tidal current } \\
\text { phase }\left(^{\circ}\right)\end{array}$ & 207 & 212 & 206 & 210 & 104 & 227 & 223 & 166 & 212 & 185 & 202 & 191 & 232 \\
\hline
\end{tabular}

Envisat ASAR: Environmental Satellite's (Envisat) Advanced Synthetic Aperture Radar (ASAR); ALOS PALSAR: Advanced Land Observing Satellite's (ALOS) Phased Array type L-band Synthetic Aperture Radar (PALSAR). 


\section{Results}

\subsection{Bathymetric Features over the Tidal Channel on Synthetic Aperture Radar Imagery}

From Figures 1 and 2, one can see that the bright stripes on the SAR images over the study area are similar to the general pattern of underwater topography in the region. By comparing these with the bathymetric data, the relationship can be seen more clearly. Figure 3a illustrates an example of the SAR images with the contours of the water depth. The tidal channel features are roughly aligned along the $10 \mathrm{~m}$ and $20 \mathrm{~m}$ depth contour lines in the region. In comparison with the gradient of the water depth, it is clearly shown that the bright radar intensity areas are exactly coincident with the maximum depth gradient lines (Figure 3b). These drastic changes in water depth induce distinctive underwater topographic signatures by interacting with the strong tidal current prevailing in the study area. When flowing over deeper areas, the velocity of the sea surface tidal current decreases, giving rise to convergent zones where the waves are squeezed. This leads to an increase in the amplitude of the Bragg waves and hence, an increase in the radar backscatter. Therefore, an enhanced image intensity appears on the convergent areas. For this case, the tidal currents over the underwater bathymetric features flow southwestward to the major axis of the tidal channel so that concentrated convergence flow regimes are formed on the south side of the underwater topography.

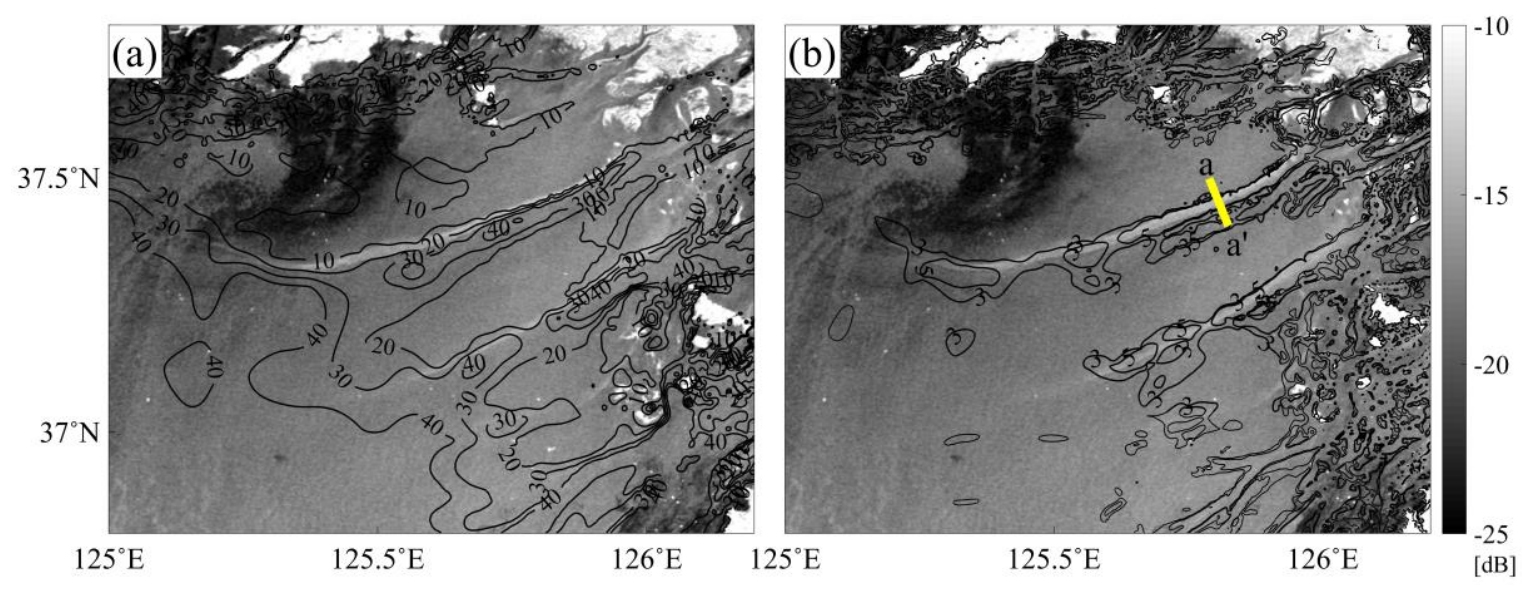

Figure 3. The distribution of normalized radar cross sections (NRCSs) from the SAR image acquired on 11 December 2007, with contours of (a) water depth $(\mathrm{m})$ and (b) its gradient, where the yellow line $\left(\mathrm{a}-\mathrm{a}^{\prime}\right)$ represents the section crossing the maximum depth gradient line.

Figure 4 presents the SAR sub-scene images of the study area. The SAR images of the tidal channels show obvious bathymetric features spread out from the river estuary, irrespective of acquisition frequency (C- or L-band) and polarization state (VV- or HH-polarization). While some sea surface manifestations of atmospheric lee waves around islands are partly imprinted as well, the most prominent features are two bright curved line features in the middle part of the images. Most of the images over Gyeonggi Bay show these distinct tidal channel signatures, except for one which was acquired on 11 July 2009. Considering the environmental parameters at the image acquisition time, it is inferred that a low wind condition with a speed of $2.4 \mathrm{~m} / \mathrm{s}$ was the primary cause for this specific case being different to all the other cases. Underwater topographic features can be imprinted on radar images through the modulation of the small-scale surface roughness generated by wind-waves with underwater topography. Thus, the capability of radar imaging for underwater topography relies on the presence of Bragg waves, meaning that wind speed should be above the threshold for small-scale water wave generation (i.e., above $2-3 \mathrm{~m} / \mathrm{s}$ ). Except for one, all cases in the study satisfied the wind conditions for SAR underwater topography imaging, varying from 3.1-9.3 m/s. 

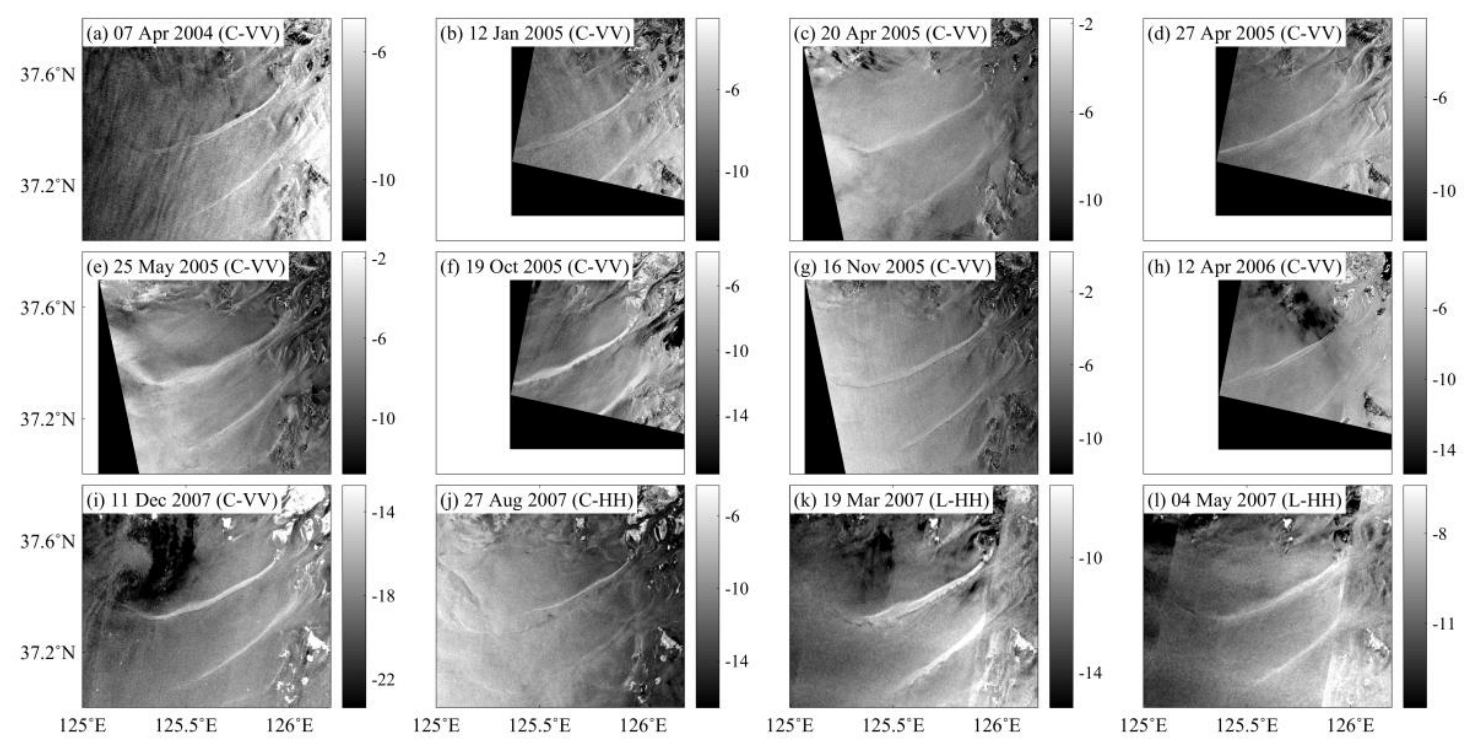

Figure 4. Sub-scenes of SAR images with dB units in the study area on (a) 7 April 2004, (b) 12 January 2005, (c) 20 April 2005, (d) 27 April 2005, (e) 25 May 2005, (f) 19 December 2005, (g) 16 November 2005, (h) 12 April 2006, (i) 11 December 2007, (j) 27 August 2007, (k) 19 March 2007, and (l) 4 May 2007. The images in $(\mathbf{a}-\mathbf{i})$, $\mathbf{j})$, and $(\mathbf{k}, \mathbf{l})$ were observed with C-band VV-polarization, C-band HH-polarization, and L-band HH-polarization, respectively.

The signatures on the SAR images are nearly parallel to each other. While the lower one is not clearly shown in this case (e.g., Figure 4j), the other one persistently appears on all the images. Since the imaging patterns of the signatures seem similar and full coverage of the lower ones are restricted in Figure $4 \mathrm{~d}, \mathrm{f}, \mathrm{h}$, we examined the signature variations by focusing on the upper main tidal channel feature. The main linear feature has a length of approximately $52 \mathrm{~km}$ and, in these cases, stretches outside the sand banks, consistent with a tail-like feature and a total length of $69 \mathrm{~km}$. The tidal channel signatures in the study area were imaged in various shapes and brightness levels under the same radar parameter condition. In the case of C-band VV-polarization, a series of tidal channel signatures on the SAR images demonstrated substantial changes in width and brightness contrast, as shown in Figure 4a-i. In particular, the differences between the NRCS values over the tidal channels and neighboring sea surface varied over a range of $2 \mathrm{~dB}$.

For the statistical investigation of the tidal channel signature variations, the features on the SAR images were extracted based on the objective detecting method. Pixels with bathymetric features indicate distinguished radar backscattering properties compared to those on the sea surface without these features. In particular, the tidal channel signatures in the study area showed very distinct differences from the neighboring background for any radar imaging condition. Figure 5 presents histograms of the NRCS values extracted from small areas over the tidal channel signature and calm backgrounds in the calibrated SAR images acquired at each imaging condition. For all cases, similar distribution patterns were shown, which indicates much higher NRCS values over the bathymetric features readily distinguished from the background. Thus, it is believed that discrimination of the bathymetric features by the adaptive thresholds can be effectively performed for the cases in the study. Figure 6 demonstrates examples of tidal channel feature detection from the SAR images. The locations and shapes of the tidal channel signatures were extracted by the objective thresholding method. Preliminary tidal channel signatures (Figure $6 \mathrm{~b}, \mathrm{e}$ ) were extracted by the adaptive thresholding method from incidence-angle-dependence corrected NRCSs (Figure 6a,d), and then the edges of the tidal channel signatures (Figure $6 \mathrm{c}, \mathrm{f}$ ) were delineated from the detection results. As shown in Figure $6 \mathrm{~b}, \mathrm{e}$, the elongated feature lines, spanning a range of directions, were more uniformly detected after 
incidence angle normalization, in comparison to those without incidence angle correction (red lines in Figure $6 b, e)$.
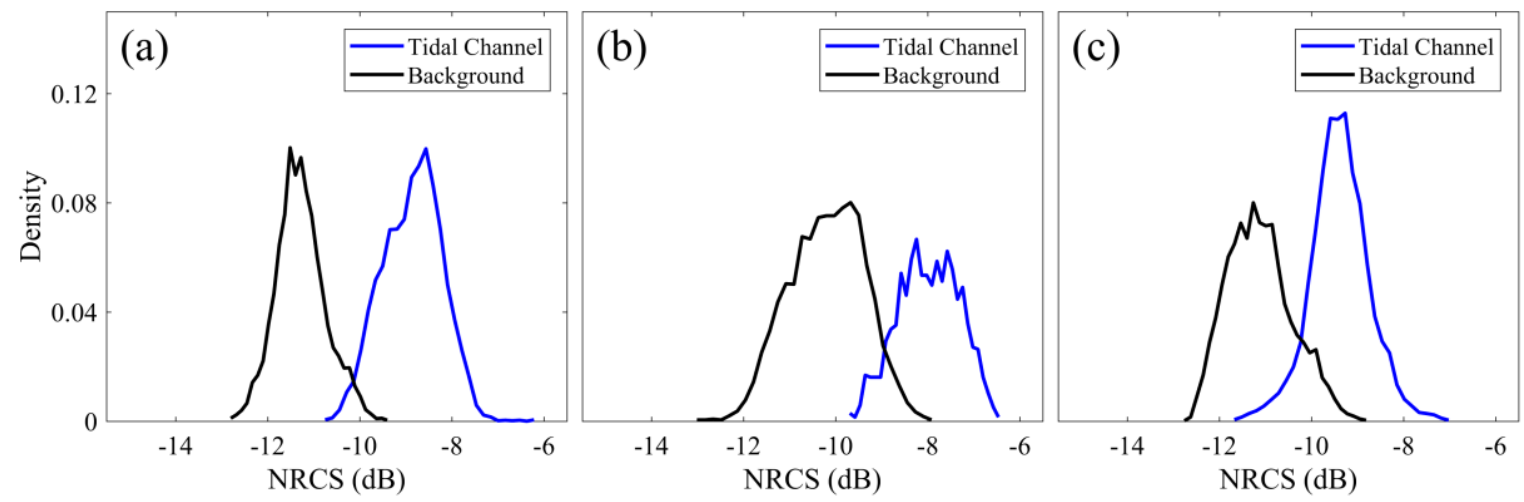

Figure 5. Density histograms of NRCS values from the region over the tidal channel and the background, acquired (a) on 20 April 2005 with C-band VV-polarization, (b) on 27 August 2007 with C-band, HH-polarization, and (c) on 19 March 2007 with L-band, HH-polarization, respectively. A low-pass filter was applied to smooth the speckle noise.
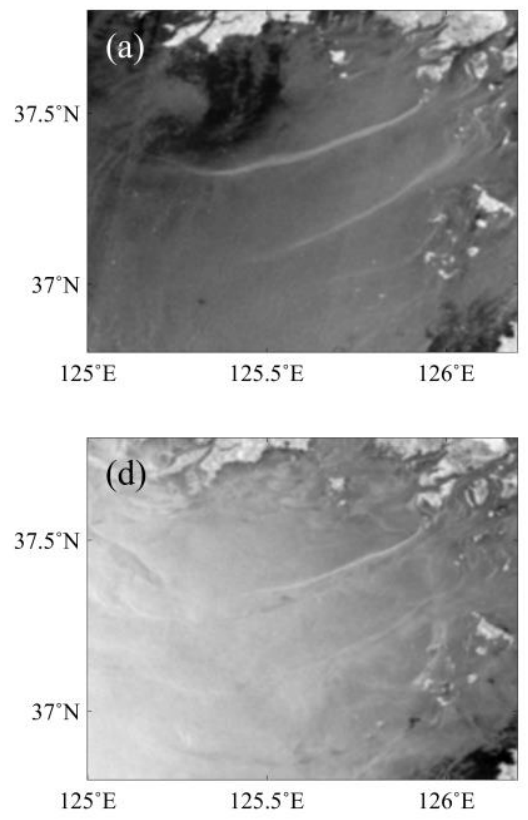

(b)

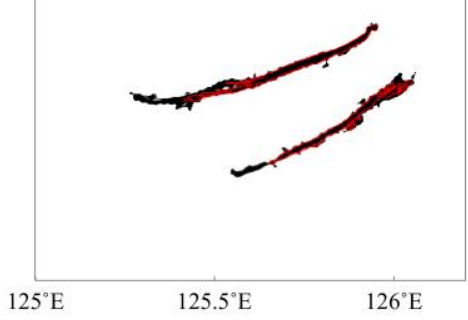

(e)

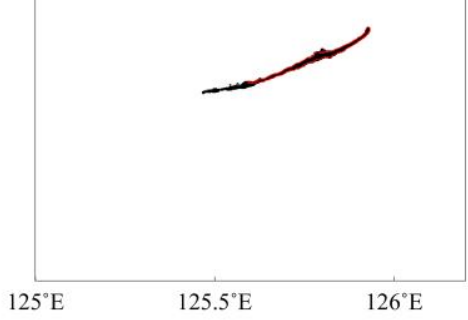

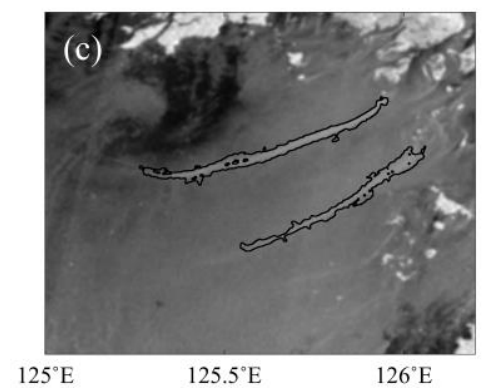

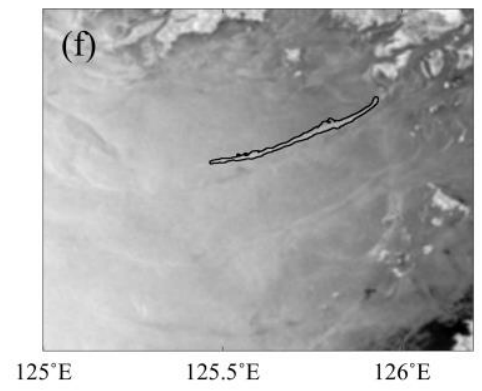

Figure 6. Examples of detected tidal channel features. Distributions of sigma nought after incidence angle normalization (a) on 11 December and (d) 27 August 2007, respectively. (b,e) are the detected features after incidence angle normalization, where the red edge lines indicate detected features from those without incidence angle normalization, and $(\mathbf{c}, \mathbf{f})$ are the edge boundaries which were extracted by Canny edge detection overlaid on the SAR sub-scenes.

Figure 7 illustrates the extracted edges of tidal channel signatures with the distribution of tidal currents at the image acquisition time. In most cases (11 of 13), tidal currents mainly flowed over the underwater bathymetric features southwestward or southward in a direction which is oblique to the major axis of the tidal channel, with an angle from 16.9-63.9 ${ }^{\circ}$. For the rest of cases, the tidal currents showed weakly eastward flows over the tidal channel but still headed to the south. Thus, the convergence-induced intensity enhancement regions appear on the south side of the maximum water depth gradient line for all cases. In terms of shapes, the extracted features revealed higher variability in width than in length. The widths of the features on the images ranged from $0.4-3.0 \mathrm{~km}$, 
while the lengths were consistent within the main tidal channel line, excluding the extended curved tail-like features over the sand banks.
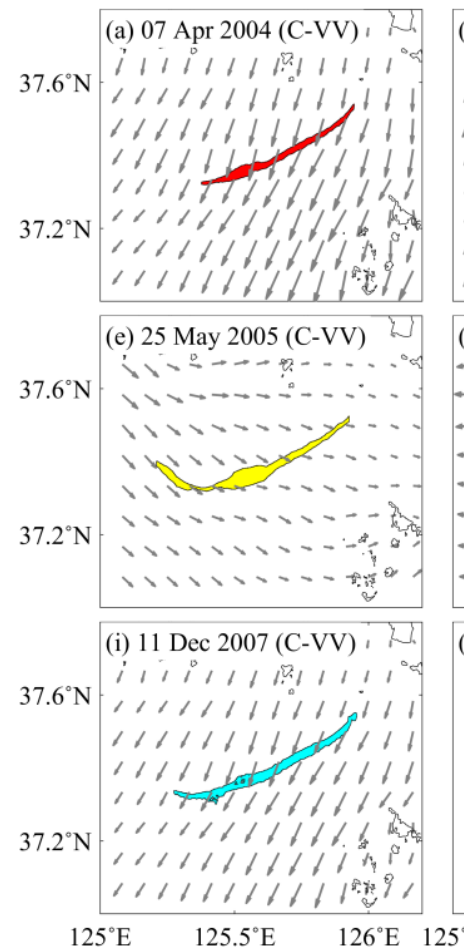
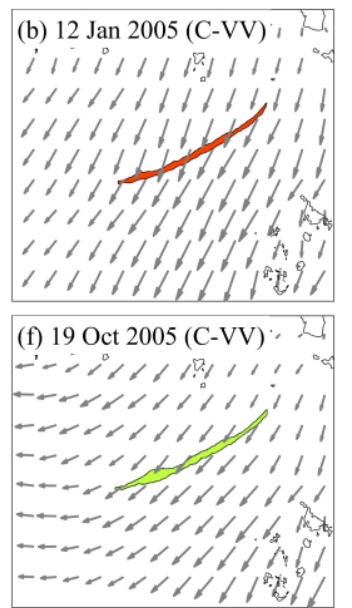

\section{(j) 27 Aug 2007 (C-HH)}

$i 1 i \backslash 11 \nabla_{i}$

$1+111+111$
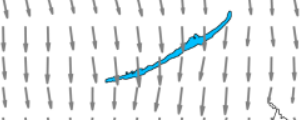

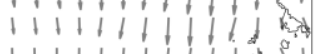

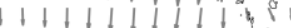

111111111090

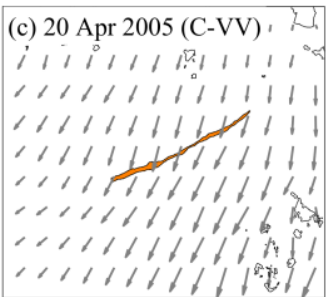

(g) 16 Nov 2005 (C-VV) $>$ ?

(g) 16 Nov $2005(\mathrm{C}-\mathrm{VV})$

-

$x+4+11+101+1$

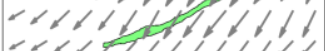

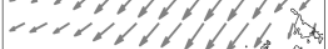

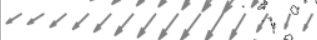

$20+1616161.169$

(k) 19 Mar 2007 (L-HH) '

$i 11 i 1110.11111^{\circ}$

1,1111111111

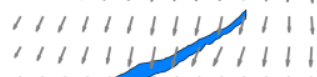

$1,1,1,111111$

1,111111166

1,1111111001

111111111091

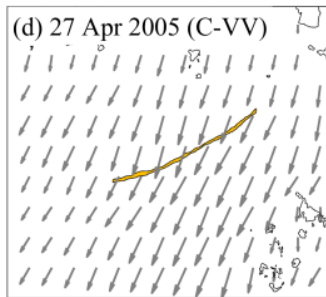

(h) 12 Apr 2006 (C-VV)

i i i

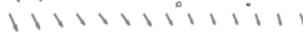

$111111111 / 1111$

$111111+11111$

111111111111 .

$11111111111^{2} 8^{2}$

111111111111 然?

(1) 04 May 2007 (L-HH)

i i i i i i i i i i 1

$1111111111+11$

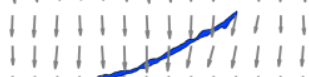

1111 म11111:

$111111111111 \mathrm{~b}$

$1 \mathrm{~m} / \mathrm{s} 1+1+1 \mid 11^{2} \mathrm{p}_{1}$

$\mathrm{m} / \mathrm{s}+1+1+1 / 1)$

Figure 7. Underwater bathymetric features over the tidal channel, extracted from the SAR images by the objective detection method. The background vector fields indicate tidal currents at the image acquisition time.

\subsection{Modulation of Tidal Channel Signatures}

Figure 8 presents the variation in the relative NRCSs from the mean NRCS values of the background along the cross section, a-a', in Figure 3b. The positive values of the NRCS variations correspond to the bright streaks on the SAR images. Although the ranges of the most positive values are located within $2 \mathrm{~km}$ southeastward from the maximum depth gradient line, the peaks of the SAR signals do not take place exactly at the same location. One of the possible reasons for this is that the bathymetry of the study area steadily changed under the influence of strong tidal currents [36,37]. Regular in-situ surveying by the Korea Hydrographic and Oceanographic Agency (KHOA) in Gyeonggi Bay verified a short-term migration of sand ridges over tens of meters in a month [38]. Furthermore, since the slope of the tidal channel in the study area is very steep and the water depth from the sea surface to the bottom is liable to change due to significant sea level fluctuations by tide, the locations of the peaks of the NRCS values can be shifted over time.

From Figure 8, one can see that magnitude of the NRCS variation differed between tidal signatures. The variation in NRCS between the tidal channel signatures ranged from 1.31-4.59 dB. It is known that these radar imaging mechanisms of underwater topography generally involve the following three processes: (i) The interaction of the current with underwater topographic features (current-bottom topography interaction); (ii) the modulation of the short-scale, wind-generated waves by surface currents over underwater topographic features (wave-current interaction); and (iii) the variation in backscatter on radar images induced by interaction of the electromagnetic waves with the sea surface (radar-ocean wave interaction). As is the case in the study area, the dominant surface current is a tidal current in most cases. It has been accepted that current convergence and divergence over the topography is mainly governed by the variable flows perpendicular to the sand ridge. This NRCS modulation can be expressed as a one-dimensional continuity equation under simplified 
assumptions for velocity components normal to the sand ridge [1]. On the other hand, as mentioned in the introduction, it has also been demonstrated that tidal currents parallel to the major axis of the underwater topography modulate in the surface flow fields, which, in turn, causes surface convergence and divergence $[7,11,12]$. These surface convergence and divergence zones induced by the interaction of the along-underwater-ridge current and sand ridges are imaged in various radar intensity modulations on the SAR images. Consequently, we then further examined the contribution of the along- and across-flows to the NRCS modulation, with tidal currents separated into components parallel and perpendicular to the major axis of the tidal channel signatures.

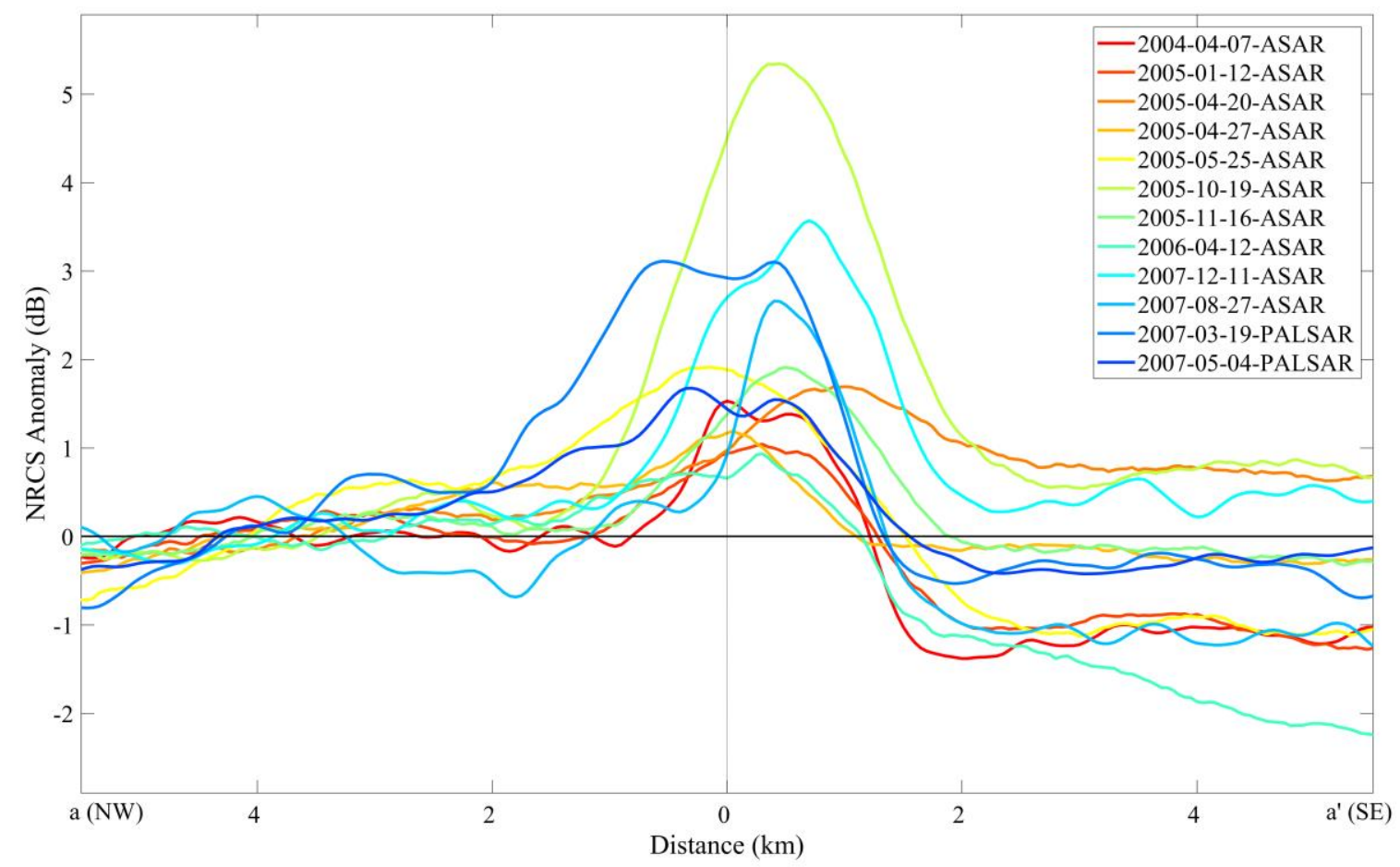

Figure 8. Variations in NRCS anomaly values $(\mathrm{dB})$ along the section, a-a', in Figure 3b.

\subsection{Effects of Tidal Current and Wind on Normalized Radar Cross Section Variation}

Radar backscatter features over the same tidal channel variably appear on the SAR imagery depending to the environmental conditions at the time of imaging. It has been reported that the composite interaction of ambient tidal currents over the tidal channel with blowing wind at the image acquisition time contribute to the distinctive variability in the underwater bathymetric features. In this study, we paid more attention to the impacts of each of the parameters on the NRCS variability.

By examining in-situ measurements and model data, we investigated the contribution of the tidal current and wind to the SAR imaging of tidal channel signatures. Figure 9 illustrates a comparison of tidal current components with the NRCS variations, where the dashed lines indicate the least-squares fitting lines of the C-band VV-polarization cases. The variation in the NRCS values had a positive correlation with the perpendicular components of the tidal current (Figure 9a). As the current flow normal to the tidal channel was enhanced, the magnitude of the NRCS modulation signature tended to increase ( $r=0.47$ within a $90 \%$ confidence level). Contrarily, the NRCS modulation tendency related to the parallel components was not shown clearly $(r=0.12)$. These different aspects of the modulations are believed to be due to the disparate influences of the mechanisms for each surface current convergence and divergence interaction. The relationship between SAR image intensity and the perpendicular components of tidal currents is explained by the existing theory of underwater topography imaging mechanisms. In this case, cross-current flows induce definite convergence and divergence over the ridges. Assuming simplification of the underwater imaging condition, hydrodynamic modulation 
generated by the current component normal to the major axis of the ridge is given by an action balance equation. According to the underlying equation, the modulation of NRCS over the underwater features is proportional to the cross-ridge current velocity as well as the water depth and its gradient [1]. The statistical results of the study support this theoretical model. On the other hand, tidal flows parallel to the ridges also produce surface convergence and divergence through secondary circulation around the underwater topography. This variation in the surface current field induces the modulation of radar backscatter which can appear on the SAR images as relatively bright stripes; however, their variation in intensity is much smaller than those induced by the cross-tidal flows [7,22]. In particular, modulation in radar intensity over ridges, which are theoretically calculated from a two-dimensional analytical tidal model, demonstrate a nonlinear relationship with along-tidal-channel flow velocity, yielding much-reduced NRCS values. When the magnitude of the current is reduced by half, the derived NRCS variation is reduced by a quarter, not by half [7]. Compared to the results of this study (2.5 dB, Case 10 in Table 1), both the observed and simulated results from the along-tidal-channel interaction indicate much smaller ranges of variation $(1.2 \mathrm{~dB})$ under similar imaging conditions. Thus, it can be inferred that the magnitude of tidal channel signature modulation primarily depends on the cross-channel velocity.
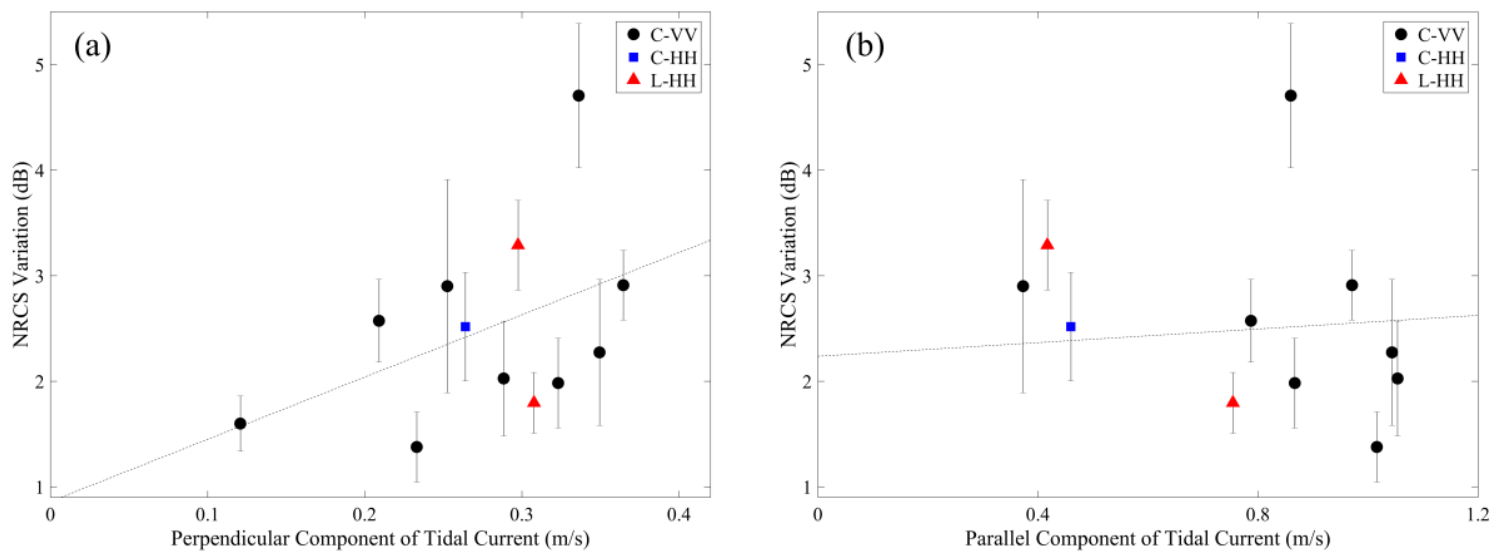

Figure 9. Relationship between the tidal current and variation in the NRCS (dB). NRCS variations in tidal channel signatures as a function of magnitude of (a) perpendicular and (b) parallel components of the tidal current $(\mathrm{m} / \mathrm{s})$.

The modulation of the short water waves interacting with the surface current and underwater ridges was imprinted as a sea surface manifestation of underwater topography on the radar image. Thus, the wind condition is assumed to be another main factor responsible for variation in NRCS in the tidal channel signatures. Figure 10 presents the variation in the NRCS as a function of wind speed. The variation in NRCS showed a significant negative tendency in response to increasing wind speed ( $r=-0.65$ within a $95 \%$ confidence level). This means that the detection capability for tidal channel signatures tends to be more degraded as wind speed increases. In general, underwater topographic features can be detected by radar intensity differences between those induced by the modulation of small-scale water waves by underwater topography, and those from the sea surface background. However, the NRCS signal level on the sea surface is primarily dominated by wind speed. Assuming relatively small areas over the underwater topography, the wind within the areas is considered uniform so that the increase in wind-induced roughness works toward reducing the relative variation in intensity over the underwater topography. Thus, the results of the study confirm that an optimum range of wind speed is important in underwater topography imaging. Under high wind conditions, wind waves substantially mask the sea surface roughness modulation caused by the variable current associated with tidal flow over the sand ridges. Depending on water depth 
and current, it is generally accepted that a wind speed has to be below 10-12 m/s for detection of underwater topography $[39,40]$, similar to what is shown by the results of this study.

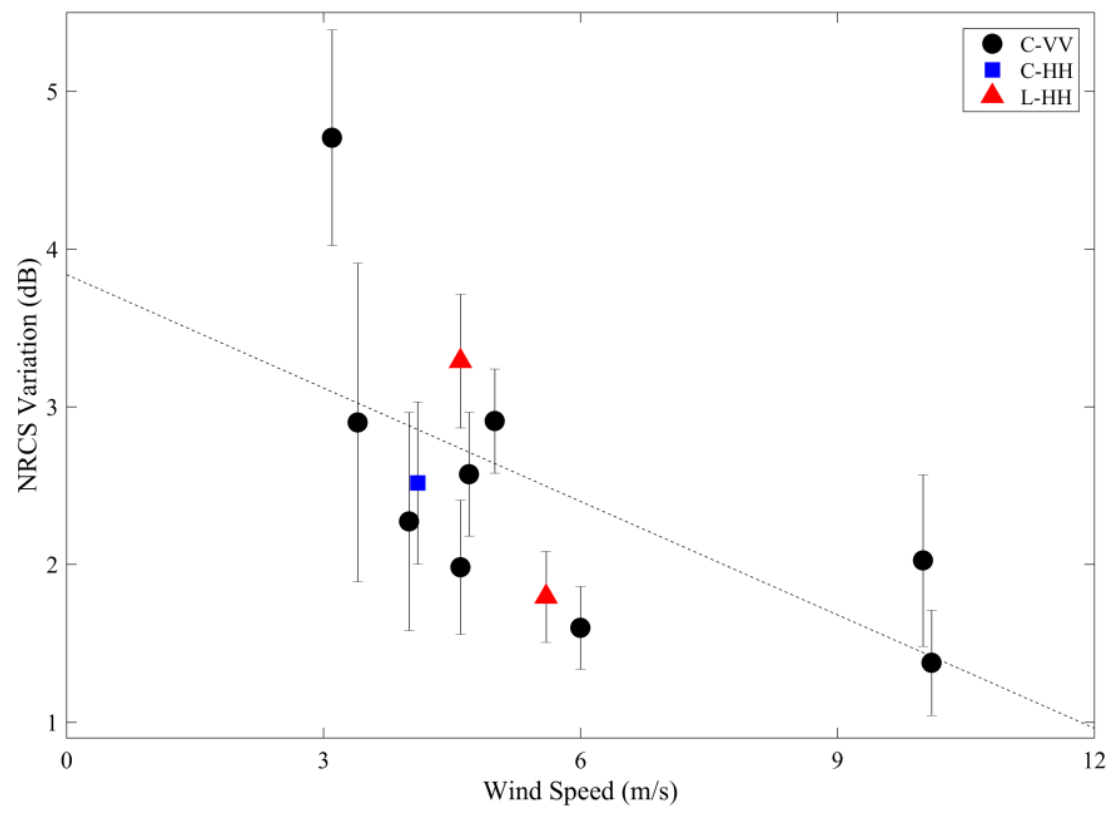

Figure 10. Relationship between the wind speed $(\mathrm{m} / \mathrm{s})$ and the variation in NRCS $(\mathrm{dB})$.

\section{Conclusions}

In this study, we analyzed a series of SAR images over Gyeonggi Bay in the Eastern Yellow Sea off the Western coast of the Korean Peninsula and investigated the modulation of the tidal channel signatures on SAR imagery. Most of the SAR images showed obvious bathymetric features, irrespective of acquisition frequency and polarization state, while the tidal channel signatures in the study area were imaged in various shapes and brightness levels. For the statistical analysis, the underwater topographic features were extracted by an objective method. A comparison of the extracted underwater topographic signatures and tidal currents showed a tendency for the variation in NRCS to primarily increase with the magnitude of the tidal current component normal to ridges. Although parallel current flows generate certain convergence and divergence over the ridges for underwater topographic feature imprints, it is believed that the intensity modulation depends strongly on the interaction with cross-current flows.

In spite of large fluctuations in radar intensity, the underwater topography in the study area was persistently imprinted on the SAR images due to the shallow water depth and prevailing strong tidal currents. Significant NRCS variation induced by the ocean surface current over the underwater topography appeared, irrespective of the radar imaging conditions, in most cases. It is notable that there were also some cases where the tidal channel signatures were not clearly shown. In these cases, wind conditions may have played the most significant role in the SAR imaging of the underwater topography. As mentioned, wind is one of the most important preconditions for indirect radar imaging of underwater topographic features. Since modulation of the small-scale surface roughness by the surface current results in bathymetric features on the radar images, the wind speed must be above the threshold for small-scale wave generation. At the same time, it has also to be below the limit where the wind-generated roughness modulation obscures the sea surface modulation induced by the underwater topography. The results of this study confirm the degradation of underwater topography imaging through the decrease in NRCS variation under high winds. Thus, under the conditions of shallow bathymetry and strong tidal currents, it can be inferred that SAR's imaging capability for the detection of tidal channel signatures primarily relies on wind speed. 
Although the general aspects of underwater bathymetric features have been demonstrated through an objective analysis of a series of SAR images, more work needs to be done to validate the results. The use of more SAR data will provide more convincing evidence regarding the effects of environmental factors on the modulation of bathymetric features in SAR images. Additionally, there is a need for further work to quantitatively analyze the contributions of each of the environmental parameters on the modulation of radar intensity. The study of such effects requires the acquisition of sufficient numbers of SAR images, in conjunction with in-situ field surveys. It is very likely that this will be possible, as more satellite SAR operational programs—-for example Sentinel-1—will provide regular observations over coastal regions with a wide degree of coverage. This is an area we are pursuing, with a focus on increasing our understanding of radar imaging mechanisms related to the interaction of underwater bathymetry and environmental factors.

Acknowledgments: This research was a part of the project titled 'Development of Management Technology for HNS Accident', funded by the Ministry of Oceans and Fisheries, Korea. Data processing was supported by a grant from the Endowment Project of "Development of Technology to Support the Rapid Search and Rescue of Marine Accidents" funded by Korea Research Institute of Ships and Ocean engineering(PES9370).

Author Contributions: T.-S. K., K.-A. P., and M. L. contributed to the concept of the paper. T.-S. K. processed the SAR data and wrote the manuscript. K.-A. P. and M. L. provided guidance on the method and interpretation of the results. M. L. supervised all the research work. All authors contributed to the discussion and revision of the manuscript.

Conflicts of Interest: The authors declare no conflict of interest.

\section{References}

1. Alpers, W.; Hennings, I. A theory of the imaging mechanism of underwater bottom topography by real and synthetic aperture radar. J. Geophys. Res. 1984, 89, 1029-1054. [CrossRef]

2. Shuchman, R.A.; Lyzenga, D.R.; Meadows, G.A. Synthetic aperture radar imaging of ocean-bottom topography via tidal-current interactions: Theory and observations. Int. J. Remote Sens. 1985, 6, 1179-1200. [CrossRef]

3. Vogelzang, J.; Wensink, G.J.; de Loor, G.P.; Peters, H.C.; Pouwels, H. 1992: Sea bottom topography with X band SLAR: The relation between radar imagery and bathymetry. Int. J. Remote Sens. 1992, 13, 1943-1958. [CrossRef]

4. Vogelzang, J.; Wensink, G.J.; Calkoen, C.J.; Van der Kooij, M.W.A. Mapping submarine sand waves with multiband imaging radar: Experimental results and model comparison. J. Geophys. Res. 1997, 102, 1183-1192. [CrossRef]

5. Hennings, I. An historical overview of radar imagery of sea bottom topography. Int. J. Remote Sens. 1998, 19, 1447-1454. [CrossRef]

6. Zheng, Q.; Li, L.; Guo, X.; Ge, Y.; Zhu, D.; Li, C. SAR imaging and hydrodynamic analysis of ocean bottom topographic waves. J. Geophys. Res. 2006, 111. [CrossRef]

7. Li, X.; Li, C.; Xu, Q.; Pichel, W.G. Sea surface manifestation of along-tidal-channel underwater ridges imaged by SAR. IEEE Trans. Geosci. Remote Sens. 2009, 47, 2467-2477.

8. Li, X.; Yang, X.; Zheng, Q.; Pietrafesa, L.J.; Pichel, W.G.; Li, Z.; Li, X. Deep-water bathymetric features imaged by spaceborne SAR in the Gulf Stream region. Geophys. Res. Lett. 2010, 37. [CrossRef]

9. Shi, W.; Wang, M.; Li, X.; Pichel, W.G. Ocean sand ridge signatures in the Bohai Sea observed by satellite ocean color and synthetic aperture radar measurements. Remote Sens. Environ. 2011, 115, 1926-1934. [CrossRef]

10. Zheng, Q.; Holt, B.; Li, X.; Liu, X.; Zhao, Q.; Yuan, Y.; Yang, X. Deep-water seamount wakes on SEASAT SAR image in the Gulf Stream region. Geophys. Res. Lett. 2012, 39. [CrossRef]

11. Wang, X.; Zhang, H.; Li, X.; Fu, B.; Guan, W. SAR imaging of a topography-induced current front in a tidal channel. Int. J. Remote Sens. 2015, 14, 3563-3574. [CrossRef]

12. Zhang, S.; Xu, Q.; Zheng, Q.; Li, X. Mechanisms of SAR imaging of shallow water topography of the Subei Bank. Remote Sens. 2017, 9, 1203. [CrossRef]

13. Kim, T.; Park, J.-J.; Choi, B.-J. Study of the tidal channels appeared on SAR images. Korean J. Remote Sens. 2009, 25, 501-505. 
14. Vogelzang, J. The mapping of bottom topography with imaging radar: A comparison of the hydrodynamic modulation in some existing models. Int. J. Remote Sens. 1989, 10, 1503-1518. [CrossRef]

15. Hennings, I. Radar imaging of submarine sandwaves in tidal channels. J. Geophys. Res. 1990, 95, $9713-9721$. [CrossRef]

16. Cooper, A.L.; Chubb, S.R.; Askari, F.; Valenzuela, G.R.; Bennett, J.R.; Keller, W.C. 1994, Radar surface signatures for the two-dimensional tidal circulation over Phelps Bank, Nantucket Shoals: A comparison between theory and experiment. J. Geophys. Res. 1994, 99, 7865-7883. [CrossRef]

17. Van der Kooij, M.W.A.; Vogelzang, J.; Calkoen, C.J. A simple analytical model for brightness modulations caused by submarine sand waves in radar imagery. J. Geophys. Res. 1995, 100, 7069-7082. [CrossRef]

18. Vogelzang, J. Mapping submarine sand waves with multiband imaging radar: 1. Model development and sensitivity analysis. J. Geophys. Res. 1997, 102, 1163-1181. [CrossRef]

19. Romeiser, R.; Alpers, W. An improved composite surface model for the radar backscattering cross section of the ocean surface: 2. Model response to surface roughness variations and the radar imaging of underwater bottom topography. J. Geophys. Res. 1997, 102, 25251-25267. [CrossRef]

20. Hennings, I.; Metzner, M.; Calkoen, C.J. Island connected sea bed signatures observed by multi-frequency synthetic aperture radar. Int. J. Remote Sens. 1998, 19, 1933-1951. [CrossRef]

21. Vogelzang, J. A model comparison study to the imaging of submarine reefs with synthetic aperture radar. Int. J. Remote Sens. 2001, 22, 2509-2536. [CrossRef]

22. Kim, T.; Park, J.; Lee, H. Spatial variation of coastal sand ridge features appeared on SAR images. J. Coast. Res. 2011, SI64, 1687-1691.

23. Park, S.C.; Lee, S.D. Depositional patterns of sand ridges in tide-dominated shallow water environments: Yellow Sea coast and South Sea of Korea. Mar. Geol. 1994, 120, 89-103. [CrossRef]

24. Choi, J.-Y.; Kwon, Y.K.; Chung, G.S. Late Quaternary stratigraphy and depositional environment of tidal sand ridge deposits in Gyeonggi Bay, west coast of Korea. J. Korean Earth Sci. Soc. 2012, 33, 1-10. [CrossRef]

25. Topouzelis, K; Singha, S. Incidence angle normalization of wide swath SAR data for oceanographic applications. Open Geosci. 2016, 8, 450-464.

26. Ulaby, F.T.; Moore, R.K.; Fung, A.K. Microwave Remote Sensing: Active and Passive Volume II: Radar Remote Sensing and Surface Scattering and Emission Theory; Artech House: Norwood, MA, USA, 1982.

27. Mladenova, I.E.; Jackson, T.J.; Bindlish, R.; Hensley, S. Incidence angle normalization of radar backscatter data. IEEE Trans. Geosci. Remote Sens. 2013, 51, 1791-1804. [CrossRef]

28. Solberg, A.H.S.; Storvik, G.; Solberg, R.; Volden, E. Automatic detection of oil spills in ERS SAR images. IEEE Trans. Geosci. Remote Sens. 1999, 37, 1916-1924. [CrossRef]

29. Solberg, A.H.S.; Dokken, S.T.; Solberg, R. Automatic Detection of Oil Spills in Envisat, Radarsat and ERS SAR images. In Proceedings of the IEEE International Geoscience and Remote Sensing Symposium (IGARSS), Toulouse, France, 21-25 July 2003.

30. Topouzelis, K.N. Oil spill detection by SAR images: Dark formation detection, feature extraction and classification algorithms. Sensors 2008, 8, 6642-6659. [CrossRef] [PubMed]

31. Kim, T.-S.; Park, K.-A.; Li, X.; Lee, M.; Hong, S.; Lyu, S.J.; Nam, S. Detection of the Hebei Spirit oil spill on SAR imagery and its temporal evolution in a coastal region of the Yellow Sea. Adv. Space Res. 2015, 56, 1079-1093. [CrossRef]

32. Öztürk, S.; Akdemir, B. Comparison of edge detection algorithms for texture analysis on glass production. Procedia Soc. Behav. Sci. 2015, 195, 2675-2682. [CrossRef]

33. Canny, J. A computational approach to edge detection. IEEE Trans. Pattern Anal. Mach. Intell. 1986, 8, 679-714. [CrossRef] [PubMed]

34. Lee, M.; Jung, J.-Y. Pollution risk assessment of oil spill accidents in Garorim Bay of Korea. Mar. Pollut. Bull. 2015, 100, 297-303. [CrossRef] [PubMed]

35. Ryan, W.B.F.; Carbotte, S.M.; Coplan, J.O.; O’Hara, S.; Melkonian, A.; Arko, R.; Weissel, R.A.; Ferrini, V.; Goodwillie, A.; Nitsche, F.; et al. Global multi-resolution topography synthesis. Geochem. Geophys. Geosyst. 2009, 10, Q03014. [CrossRef]

36. Choi, D.-L.; Kim, S.R.; Suk, B.-C.; Han, S.-H. Transport of sandy sediments in the Yellow Sea off Tae-An Peninsula, Korea. J. Oceanol. Soc. Korean 1992, 27, 66-77.

37. Kum, B.-C.; Shin, D.-H. Dune Migration on an offshore sand ridge in the southern Gyeonggi Bay, Korea. Ocean Polar Res. 2013, 35, 51-61. [CrossRef] 
38. Lee, G.S.; Kim, D.C.; Seo, Y.K.; Yi, H.I.; Yoo, S. Sedimentary environment and sequence study using high resolution seismic survey in Gyunggi Bay, the Yellow Sea. Korean J. Fish. Aquart. Sci. 2009, 42, 683-694. [CrossRef]

39. Calkoen, C.J.; Hesselmans, G.H.F.M.; Wensink, G.J.; Vogelzang, J. The Bathymetry Assessment System: Efficient depth mapping in shallow seas using radar images. Int. J. Remote Sens. 2001, 22, 2973-2998. [CrossRef]

40. Alpers, W.; Campbell, G.; Wensink, H.; Zhang, Q. Underwater topography. In Synthetic Aperture Radar Marine User's Manual; Jackson, C.R., Apel, J.R., Eds.; US Department of Commerce, National Oceanic and Atmospheric Administration, National Environmental Satellite, Data, and Information Serve, Office of Research and Applications: Washington, DC, USA, 2004; pp. 245-262.

2018 by the authors. Licensee MDPI, Basel, Switzerland. This article is an open access article distributed under the terms and conditions of the Creative Commons Attribution (CC BY) license (http:/ / creativecommons.org/licenses/by/4.0/). 